PREPARED FOR THE U.S. DEPARTMENT OF ENERGY, UNDER CONTRACT DE-AC02-76CH03073

PPPL-3737

PPPL-3737

UC-70

Simulations of the Neutral-beam-induced Rotation,

Radial Electric Field, and Flow Shearing Rate in Next-step Burning Plasmas

by

R.V. Budny

August 2002

N/

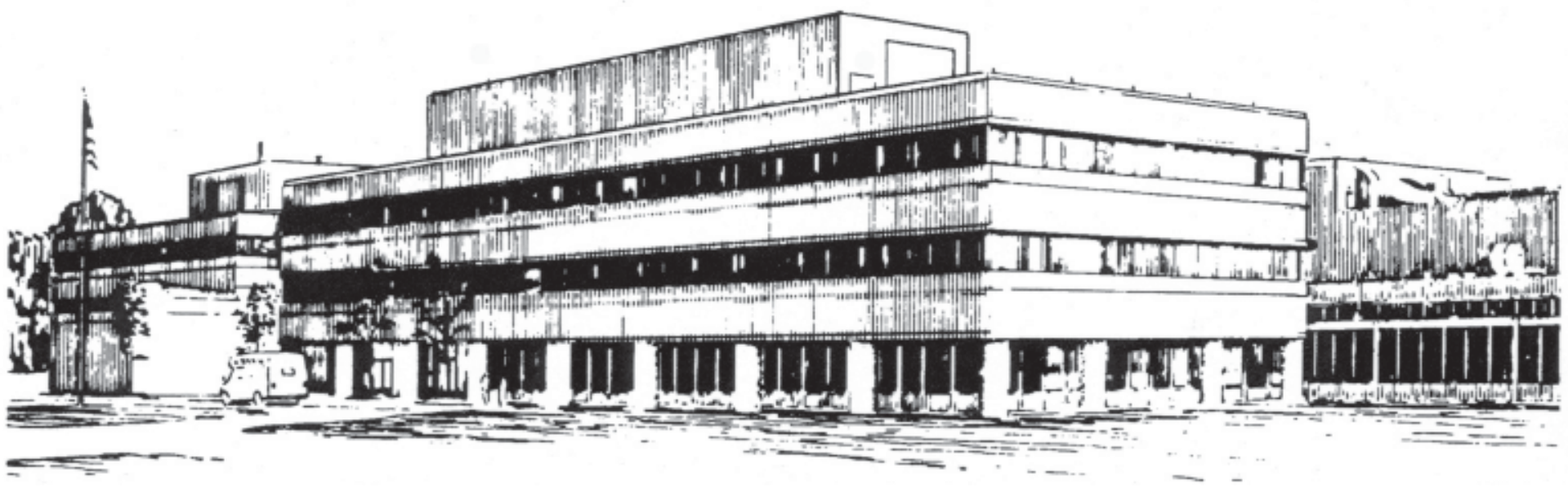

PRINCETON PLASMA PHYSICS LABORATORY PRINCETON UNIVERSITY, PRINCETON, NEW JERSEY 


\section{PPPL Reports Disclaimer}

This report was prepared as an account of work sponsored by an agency of the United States Government. Neither the United States Government nor any agency thereof, nor any of their employees, makes any warranty, express or implied, or assumes any legal liability or responsibility for the accuracy, completeness, or usefulness of any information, apparatus, product, or process disclosed, or represents that its use would not infringe privately owned rights. Reference herein to any specific commercial product, process, or service by trade name, trademark, manufacturer, or otherwise, does not necessarily constitute or imply its endorsement, recommendation, or favoring by the United States Government or any agency thereof. The views and opinions of authors expressed herein do not necessarily state or reflect those of the United States Government or any agency thereof.

\section{Availability}

This report is posted on the U.S. Department of Energy's Princeton Plasma Physics Laboratory Publications and Reports web site in Fiscal Year 2002. The home page for PPPL Reports and Publications is: http://www.pppl.gov/pub_report/

DOE and DOE Contractors can obtain copies of this report from:

U.S. Department of Energy

Office of Scientific and Technical Information

DOE Technical Information Services (DTIS)

P.O. Box 62

Oak Ridge, TN 37831

Telephone: (865) 576-8401

Fax: (865) 576-5728

Email: reports@adonis.osti.gov

This report is available to the general public from:

National Technical Information Service

U.S. Department of Commerce

5285 Port Royal Road

Springfield, VA 22161

Telephone: 1-800-553-6847 or

(703) 605-6000

Fax: (703) 321-8547

Internet: http://www.ntis.gov/ordering.htm 


\title{
Simulations of the neutral-beam-induced rotation, radial electric field, and flow shearing rate in next-step burning plasmas
}

\author{
R.V. Budny ${ }^{1}$ \\ PPPL, Princeton University, P.O. Box 451, Princeton, NJ 08543, USA
}

(16-Jul-2002)

\begin{abstract}
Toroidal rotation of plasmas in present tokamaks is beneficial for increasing the stability to wall-induced MHD and appears to reduce the anomalous transport associated with micro-turbulence. This paper calculates the toroidal rotation expected from neutral beam injection in the proposed FIRE and ITER-FEAT tokamak reactors. Self-consistent burning plasmas for these tokamaks have been constructed [1] using the TRANSP plasma analysis code. Neutral beam injection has been proposed for FIRE and ITER-FEAT. The neutral-beam-induced torques are computed, and assumptions for the anomalous transport of toroidal angular momentum are used to calculate the toroidal rotation profiles. The central Mach numbers are about 3-8 \%. The ratio of the rotation speed to the Alfvén speed is less than 1\%. Assuming neo-classical poloidal rotation and force balance, the radial electric field and flow shearing rate are calculated. Peak shearing rates near the outboard edge are in the 10-100 $\mathrm{krad} / \mathrm{s}$ range.

Classification: MO (Reactor Physics and Design)
\end{abstract}

\section{Introduction}

In present tokamak experiments, toroidal rotation of the thermal plasma is beneficial for increasing the stability to resistive wall MHD [2]. Also, toroidal rotation contributes significantly to the radial electric field, and shear in the associated ExB flow shear is correlated with enhanced confinement $[3,4]$. Tangential neutral beam injection (NBI), which is very effective in causing toroidal rotation, is being considered for two of the "next step" burning plasma tokamaks, FIRE [5] and ITER-FEAT [6,7].

The goal of this paper is to estimate the neutral-beam-induced rotation, radial electric field $E_{r}$, and flow shearing rate $\omega_{\mathrm{E} \times \mathrm{B}}$ in these next-step burning plasmas. Detailed, self-consistent $\mathbf{H}-$ mode plasmas have been constructed [1] for them using the TRANSP plasma analysis code. This paper uses these H-mode plasmas along with an "advanced tokamak" (AT) plasma constructed for FIRE having reversed magnetic shear. The results of this study are of use for evaluating the stability to resistive wall modes and micro-turbulence.

\section{Plasmas.}

\subsection{ITER-FEAT}

ITER-FEAT $[6,7]$ is designed to have super-conducting magnets for long pulse duration, and a single-null divertor geometry. The plasma is assumed to be in the ELMy H-mode regime with profiles close to those in Ref. [7] and a target DT fusion yield of $P_{D T}=400$ [MW]. Details of the TRANSP model for this plasma are given in Ref. 1. Some of the plasma parameters are summarized in Table 1.

\footnotetext{
${ }^{1}$ email: budny@princeton.edu
} 
The external heating is assumed to consist of $20 \mathrm{MW}$ of ICRH staggered with $33 \mathrm{MW}$ of NBI. This staggering allows study of the heat fluxes and fast ion parameters in three cases with the same assumed plasma profiles: $\mathrm{RF}-$ only, $\mathrm{RF}+\mathrm{NB}$, and NB-only. The NBI is assumed to consist of either 1 or $0.5 \mathrm{MeV} \mathrm{D}$ neutrals from a negative ion-beam system injected in the co-plasma current direction, at a tangency radius assumed to be $6 \mathrm{~m}$. This generates a beam-driven current profile that is broad with a total driven current of 1.1 and 0.75 MA respectively.

\subsection{FIRE}

FIRE [5] is designed to have normal-conducting magnets, and a double-null divertor geometry. The normal heating scheme is ICRH at a frequency of $100 \mathrm{MHz}$ to resonate with $\mathrm{He}^{3}$ on axis. The $P_{R F}$ is assumed to be high $(20 \mathrm{MW})$ early to provoke the $\mathbf{L}$ to $\mathbf{H}$-mode transition, and then lowered to $11 \mathrm{MW}$ as the alpha heating increases, to keep $P_{\alpha}+P_{\text {ext }}$ roughly constant. Neutral beam heating is also being considered, using one of the TFTR beam boxes delivering $8 \mathrm{MW}$ at about $110 \mathrm{keV}$. Here, the tangency radius of the NBI is assumed to be $1.7 \mathrm{~m}$. All the injection is assumed to be in the full energy component.

Two plasmas are studied, one the standard ELMy H-mode plasma described in Ref. 1, and the other an advanced tokamak (AT) scenarios with reversed magnetic shear. The AT plasma has plasma current and toroidal field reduced from the standard FIRE operating range to 5.4 MA and 8.5 T. The assumed time-evolution of the central plasma profiles and heating powers are shown in Fig. 1. The area-integrated currents and central alpha parameters are shown in Fig. 2.

Plasma profiles in the flattop are shown in Fig. 3, plotted against the toroidal flux variable, $x \equiv \sqrt{\text { normalized toroidal flux }}$, which is roughly equal to $\mathrm{r} / \mathrm{a} .15 \mathrm{MW}$ of lower hybrid (LH) current drive is assumed with a frequency of $8 \mathrm{GHz}$. The $n_{\|}$spectrum is assumed to peak at 2.0. The driven current $j_{L H}$ is calculated using the LSC code [8] incorporated into TRANSP. Profiles are shown in Fig. 4. The contributions to the plasma current at a steady state time are shown in Fig. 5. The $q_{M H D}$ profile at several times is shown in Fig. 6 .

\section{Analysis Techniques}

The TRANSP plasma analysis code [9] is used to analyze plasmas with either measured or assumed plasma profiles. TRANSP is a fixed-boundary code, so the plasma boundary is specified by assuming time evolutions of the major and minor radii, elongation, triangularity, and vertical displacement of the boundaries. The MHD equilibria are calculated in TRANSP by solving the Grad-Shafranov equation. The heat and particle fluxes are calculated from the continuity equations. The fusion alpha particles and beam ions are treated using Monte Carlo methods [10] to model their source rates, neoclassical orbits, and slowing-down rates.

Since the profiles are held fixed during the flattop phase as the heating power changes, the computed heat transport diffusivities $\chi_{\mathrm{e}}, \chi_{\mathrm{i}}$, and $\chi_{\mathrm{eff}}$, change. Profiles for the FIRE-AT plasma during a steady state phase are shown in Fig. 7. For comparison, the neoclassical prediction for $\chi_{\mathrm{i}}$ is also shown.

In the following, the radial transport diffusivity $\chi_{\text {mom }}$ of the toroidal angular momentum is assumed to be $\chi_{\mathrm{i}}$. Both can be measured in plasmas, and in JET ELMy H-mode plasmas, they 
are of the same order of magnitude [11].

The TRANSP plasma analysis code uses Monte Carlo techniques to calculate the NBI-induced torque density, $t_{N B}$ as the sum of the collisional, $\mathbf{J} \times \mathbf{B}$, ripple loss, and thermalization torques. The ripple effects are ignored here. Examples of these for the FIRE-AT plasma are shown in Fig. 8. Profiles of the computed toroidal rotation are shown in Fig. 9. The ratio of the toroidal velocity to the Alfvén velocity is shown in Fig. 10.

For the FIRE standard H-mode plasma, the transport coefficients are shown in Fig. 11. The NBI-induced torques are shown in Fig. 12. The ratio of the toroidal velocity to the Alfvén velocity is shown in Fig. 13.

For the ITER-FEAT ELMy H-mode plasma [1], the minimum value of $\chi_{\mathrm{i}}$ during the phase of maximum heating (20 MW ICRH, $33 \mathrm{MW}$ NNBI, and $75 \mathrm{MW}$ alpha) is $\mathbf{1 . 5}\left[\mathrm{m}^{2} / \mathrm{s}\right]$, as shown in Fig. 14. The collisional torque dominates in the core, and is approximately twice the magnitude of the $\mathbf{J} \times \mathbf{B}$ torque that dominates near the plasma boundary, as shown in Fig. 15. The thermalization torque is small. The ripple-loss torque is ignored here. The volume-integral of $\tau_{N B}$ is $\mathbf{4 0}[\mathrm{Nt}-\mathrm{m}]$. The volume integrals of mass density $\rho$ and $\rho R^{2} \omega_{\text {tor }}$ are 0.3 [gm] and $1.3[\mathrm{Nt}-\mathrm{m} / \mathrm{s}]$ respectively. Values are summarized in Table 2. The profiles of $\omega_{t o r}$ are shown in Figs 16. The ratio of the rotation speed to Alfvén speed, shown in Fig. 17, is comparable to the values computed for FIRE.

The flow-shearing rate can be calculated from the radial electric field, $E_{r}$, which can be calculated from the radial force balance for any thermal species, i:

$$
\begin{aligned}
& \vec{\nabla}\left(p_{i}\right)=e Z_{i}\left(\vec{E}+\vec{v}_{i} \times \vec{B}\right) \\
& E_{r}=v_{T o r, i} B_{P o l}-v_{P o l, i} B_{T o r}+\frac{1}{e Z_{i} n_{i}} \nabla\left(p_{i}\right)
\end{aligned}
$$

The $v_{T o r}$ is calculated from the NBI torque, $B_{P o l}$ is calculated from poloidal field diffusion, and $v_{P o l}$ is calculated from neoclassical theory using the NCLASS code [12] built into TRANSP. erther, $B_{T o r}$ is calculated using the dia/paramagnetic corrections to the assumed vacuum toroidal field. The toroidal rotation term dominates $E_{r}$.

The shearing rate on the outer midplane is given in terms of $E_{r}$ (Ref. [13]) by:

$\gamma_{\mathrm{E} \times \mathrm{B}}=\left(\frac{R^{2} B_{P o l}^{2}}{B}\right) \frac{\partial}{\partial \psi}\left(\frac{E_{r}}{R B_{P o l}}\right) \simeq\left(\frac{R B_{P o l}}{B}\right) \frac{\partial}{\partial R}\left(\frac{E_{r}}{R B_{P o l}}\right)$

The flow shearing rate is shown in Fig. 18.

\section{Summary and Discussion}

This paper reports results for self-consistent transport simulations of plasmas for FIRE, FIREAT, and ITER-FEAT constructed using the TRANSP analysis code. Tangential neutral beam injection is assumed, and the beam-induced torques are computed. Assuming that the anomalous rate of loss of angular momentum diffusion, $\chi_{\mathrm{mom}}$ equals that of ion heat loss, $\chi_{i}$, profiles of the toroidal rotation are computed. The resulting values, shown in Figs. 13 and 17, are less than 1\% of the Alfvén speed. In present experiments, this ratio is usually more than a few \% near the $q_{M H D}=1$ surface.

Further study is needed of the scaling of the ratio of $\chi_{\text {mom }}$ to $\chi_{\mathrm{i}}$ in present experiments. Trends in this ratio with, for instance, $\rho_{*}$ or heating would facilitate the extrapolations to future burning 
plasmas. Also, further study is needed to assess if the calculated NBI-induced rotation is sufficient to stabilize resistive wall modes in FIRE and ITER, and if the calculated flow shear is sufficient to reduce micro-turbulence.

\section{Acknowledgments}

This work was supported in part by the US DoE Contract No. DE-AC02-76CH03073. 


\begin{tabular}{|c|c|c|c|c|}
\hline Tokamak: & & ITER-FEAT & FIRE & FIRE-AT \\
\hline RUNID & & 03000A25 & $50000 \mathrm{~A} 25$ & $53000 \mathrm{~A} 17$ \\
\hline steady state time & {$[\mathrm{s}]$} & 180.0 & 20.0 & 20.0 \\
\hline $\mathrm{R}(1)$ & {$[\mathrm{m}]$} & 6.2 & 2.14 & 2.14 \\
\hline $\mathrm{a}(1)$ & {$[\mathrm{m}]$} & 2.0 & 0.60 & 0.60 \\
\hline$\kappa(1)$ & & 1.80 & 2.00 & 1.85 \\
\hline$\delta(1)$ & & 0.49 & 0.49 & 0.49 \\
\hline$P_{v o l}(1)$ & {$\left[m^{3}\right]$} & 820 & 27.2 & 27.2 \\
\hline$B_{\text {Tor }}$ & {$[\mathrm{T}]$} & 5.2 & 9.6 & 8.5 \\
\hline$I_{p}$ & {$[\mathrm{MA}]$} & 15.0 & 7.7 & 5.4 \\
\hline$I_{\text {beam }}$ & {$[\mathrm{MA}]$} & 1.1 & 0.1 & 0.1 \\
\hline$I_{b o o t}$ & {$[\mathrm{MA}]$} & 2.25 & 1.8 & 2.4 \\
\hline$I_{L H C D}$ & [MA] & 0.0 & 0.0 & 0.7 \\
\hline$q_{M H D}(1)$ & & 3.8 & 3.9 & 5.1 \\
\hline$P_{N B}$ & {$[\mathrm{MW}]$} & 33.0 & 8.0 & 8.0 \\
\hline$P_{R F}$ & {$[\mathrm{MW}]$} & 20.0 & 11.0 & 11.0 \\
\hline$P_{L H}$ & {$[\mathrm{MW}]$} & 0.0 & 0.0 & 15.0 \\
\hline$T_{e}(0)$ & {$[\mathrm{keV}]$} & 23.5 & 11.9 & 15.0 \\
\hline$<T_{e}>$ & {$[\mathrm{keV}]$} & 10.0 & 7.2 & 8.5 \\
\hline$T_{i}(0)$ & {$[\mathrm{keV}]$} & 19.5 & 11.9 & 15.0 \\
\hline$<T_{i}>$ & {$[\mathrm{keV}]$} & 5.2 & 7.2 & 8.5 \\
\hline$n_{e}(0)$ & {$\left[10^{20} / \mathrm{m}^{3}\right]$} & 1.02 & 4.90 & 3.63 \\
\hline $\bar{n}_{e}$ & {$\left[10^{20} / \mathrm{m}^{3}\right]$} & 1.00 & 4.00 & 3.00 \\
\hline$<n_{e}>$ & {$\left[10^{20} / \mathrm{m}^{3}\right]$} & 0.98 & 3.40 & 2.60 \\
\hline $\bar{n}_{e} / \bar{n}_{\text {Greenwald }}$ & & 0.62 & 0.59 & 0.62 \\
\hline$Z_{e f f}(0)$ & & 1.54 & 1.39 & 1.39 \\
\hline$\tau_{E, t h}$ & [sec] & 3.0 & 0.79 & 0.46 \\
\hline$\tau_{I P B 9(y, 2)}$ & [sec] & 3.2 & 0.79 & 0.36 \\
\hline$\beta_{n}$ & & 1.9 & 1.64 & 2.19 \\
\hline
\end{tabular}

Table 1. Summary of boundary and plasma parameters at a steady state time. All the parameters are inputs except $I_{\text {boot }}$ (calculated using the NCLASS code [12]), I $I_{\text {beam }}$, and $q_{M H D}$ (calculated accounting for poloidal field diffusion). The time-evolving geometry of the boundary $(x=1)$ is specified. 


\begin{tabular}{|c|c|c|c|c|}
\hline Tokamak: & & ITER-FEAT & FIRE & FIRE-AT \\
\hline RUNID & & 03000A25 & $50000 \mathrm{~A} 25$ & 53000A17 \\
\hline$R_{\perp}$ & {$[\mathrm{m}]$} & 6.0 & 1.7 & 1.7 \\
\hline$E_{I N J}$ & {$[\mathrm{MeV}]$} & 1.0 & 0.12 & 0.12 \\
\hline$P_{I N J}$ & {$[\mathrm{MW}]$} & 33.0 & 8.0 & 8.0 \\
\hline$<E_{b m}(0)>$ & {$[\mathrm{MeV}]$} & 0.41 & 0.051 & 0.026 \\
\hline$\tau_{b m, s l o w}(0)$ & [sec] & 1.14 & 0.020 & 0.026 \\
\hline $\int d V \rho$ & {$[\mathrm{gm}]$} & 0.3 & 0.036 & 0.027 \\
\hline $\int d V \rho R^{2} \omega_{t o r}$ & {$[\mathrm{Nt}-\mathrm{m} / \mathrm{s}]$} & 22.0 & 1.5 & 1.3 \\
\hline $\int d V \tau_{\text {tor }}$ & {$[\mathrm{Nt}-\mathrm{m}]$} & 0.3 & 0.036 & 0.027 \\
\hline$\tau_{m o m}(1)$ & {$[\mathrm{s}]$} & 0.53 & 0.18 & 0.15 \\
\hline$\omega_{t o r}$ & [kradians/s] & 4.8 & 9.4 & 12.0 \\
\hline$v_{\text {tor }}(0) / v_{\text {Alfvén }}(0)$ & $\%$ & 0.4 & 0.3 & 0.5 \\
\hline
\end{tabular}

Table 2. Summary of NBI and torque-related parameters. The NBI injection tangency radii $R_{\perp}$, energies $E_{I N J}$, powers $P_{I N J}$, and plasma mass densities $\rho$ are inputs. The $N B$ ion average energies $E_{b m}$, slowing down times $\tau_{b m, s l o w}$, and toroidal torques $\tau_{\text {tor }}$, are calculated in TRANSP using Monte Carlo methods. The toroidal rotation $\omega_{\text {tor }}$ is calculated assuming $\chi_{m o m}=\chi_{\mathrm{i}}$. The angular momentum confinement times $\tau_{m o m}$ are calculated from the angular momentum loss rates. 


\section{References}

[1] R.V. Budny, PPPL Report 3674-revised (2002), submitted for publication

[2] A.M. Garofalo, A.D. Turnbull. E.J. Strait, et al., Phys. of Plasmas, 6 (2002) 1893.

[3] R.V. Budny, B. Alper, D.N. Borba, J.G. Cordey, et al., Nucl. Fusion, 42 (2002) 66.

[4] R.V. Budny, R. Andre, A. Bécoulet, C.D. Challis, et al., Plasma Phys. and Contr. Fusion 44 (2002) 1215.

[5] D. Meade et al., presented at the Eighteenth International Conference on Plasma Physics and Controlled Fusion Research, Sorrento, Italy, 4-10 October 2000. The web site for FIRE is http://fire.pppl.gov.

[6] http://www.itereu.de

[7] D.J. Campbell, Phys. Plasmas 8 (2001) 2041.

[8] D. W. Ignat, B.P. LeBlanc, C.K. Phillips, J. R. Wilson, and R.V. Budny, "Computational Model for Fast Wave Current Drive," Proc. 11th Conf. on Radio Frequency Power in Plasmas, (Palm Springs, CA, May 1995)

[9] R.V. Budny, M.G. Bell, A.C. Janos, et al., Nucl. Fusion 35 (1995) 1497, and references therein.

[10] R.J. Goldston, D.C. McCune, H.H. Towner, S.L. Davis, et al., J. Comput. Phys. 43 (1981) 61.

[11] R.V. Budny, B. Alper, D.N. Borba, et al., Nucl. Fusion 42 (2002) 66. [12] T.S. Hahm and K.H. Burrell, Phys. Plasmas 2, 1648 (1995)

[13] W. Houlberg, K. Shang, S. Hirshman, and M. Zarnstorff, Phys. Plasmas 4 (1997) 3230. 
Figure Captions

Fig. 1 - Evolution of plasma and heating parameters assumed for the FIRE AT plasma.

Fig. 2 - Evolution of the surface-area-integrated currents and central alpha parameters in the FIRE AT plasma.

Fig. 3 - Profiles of steady-state plasma temperatures and densities assumed for the FIRE AT plasma.

Fig. 4 - Profiles of lower-hybrid-driven currents in the FIRE AT. The driven current moves out in radius as the density and temperatures increase to their steady state values.

Fig. 5 - Profiles of plasma currents in the FIRE AT plasma.

Fig. 6 - Profiles of $q_{M H D}$ in the FIRE AT plasma.

Fig. 7 - Profiles of thermal energy transport coefficients computed for the FIRE AT plasma. The neoclassical ion transport profile is calculated using the NCLASS model [11] incorporated in TRANSP. The FIRE AT plasma is conservative in the sense that the ion transport rate is much larger than $\chi_{i, n e o}$. The faint $\chi_{\mathrm{i}}$ line gives the profile for the case where there is no NBI heating but with the same plasma profiles.

Fig. 8 - Profiles of NBI-induced torque densities on the FIRE AT plasma. The total is dominated by the JxB contribution near the edge.

Fig. 9 - Profiles of the toroidal rotation computed for the FIRE AT plasma. Note that $\omega_{t o r}$ is relatively high before the plasma density ramps up to the steady state profile.

Fig.10 - Profiles of the ratio of the toroidal rotation to Alfvén speeds in the FIRE AT plasma.

Fig.11 - Profiles of heat transport diffusion coefficients computed for the FIRE AT plasma.

Fig.12 - Profiles of NBI-induced torque densities in the FIRE H-mode plasma. The total is dominated by the $\mathrm{J} \times \mathrm{B}$ contribution near the edge.

Fig.13 - Profiles of the ratio of the toroidal rotation to Alfvén speeds in the FIRE H-mode plasma. Fig.14 - Profiles of heat transport diffusion coefficients computed for the FIRE AT plasma.

Fig.15 - Profiles of NNBI-induced torque densities on the ITER-FEAT H-mode plasma. The total is dominated by the collisional drag in the core and the $\mathrm{JxB}$ contribution near the edge.

Fig.16 - Profile of the toroidal rotation rate in the ITER-FEAT H-mode plasma assuming $\chi_{\phi}=$ $\chi_{i}$.

Fig.17 - Profile of the ratio of the toroidal rotation speed to Alfvén speed in the ITER-FEAT H-mode plasma assuming $\chi_{\phi}=\chi_{i}$.

Fig.18 - Profiles of the NBI-induced flow shearing rate in the FIRE H-mode plasma. 


\section{Evolution of central plasma parameters in FIRE-AT}

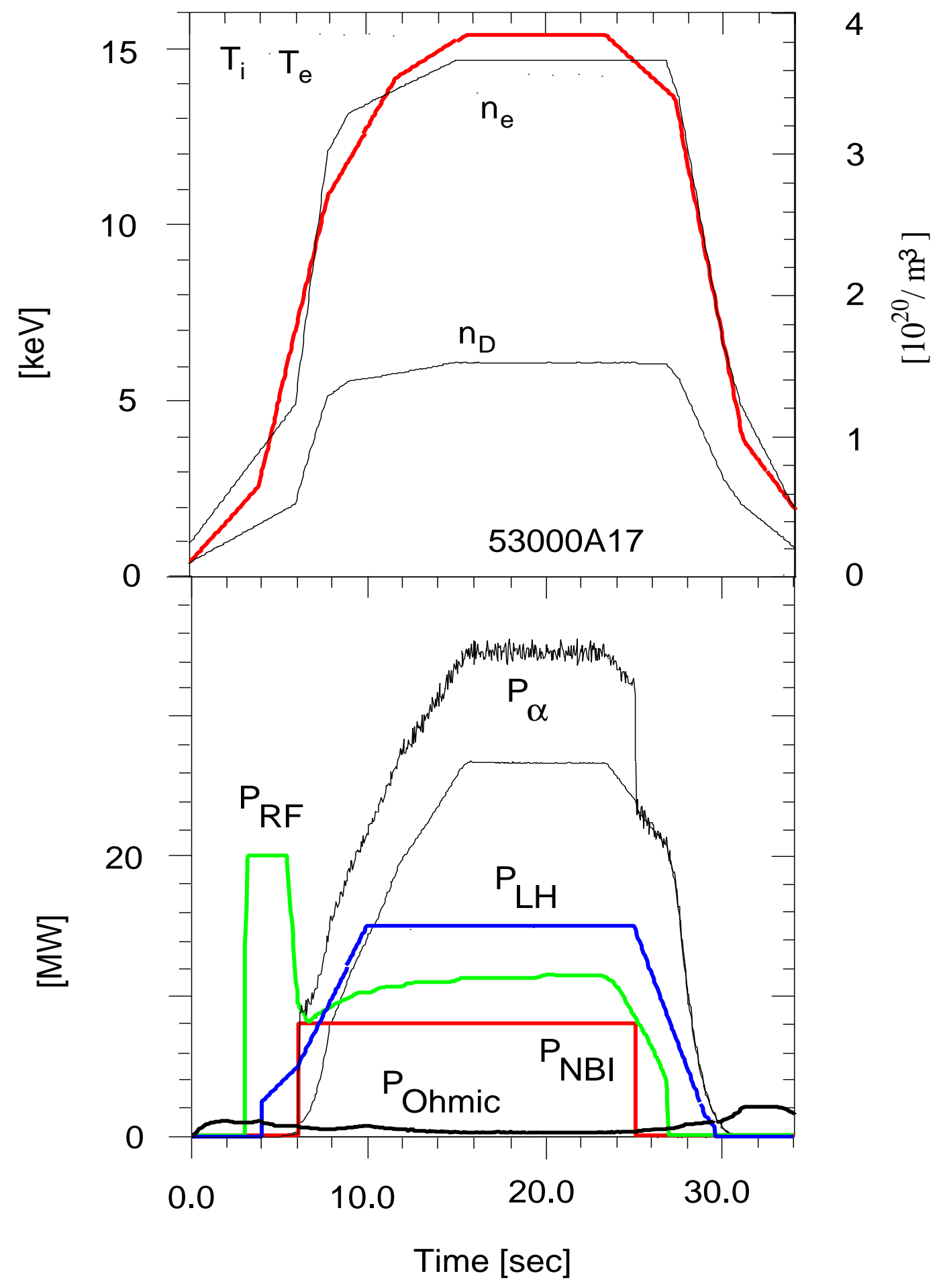

Figure 1. Evolution of plasma and heating parameters assumed for the FIRE AT plasma. 


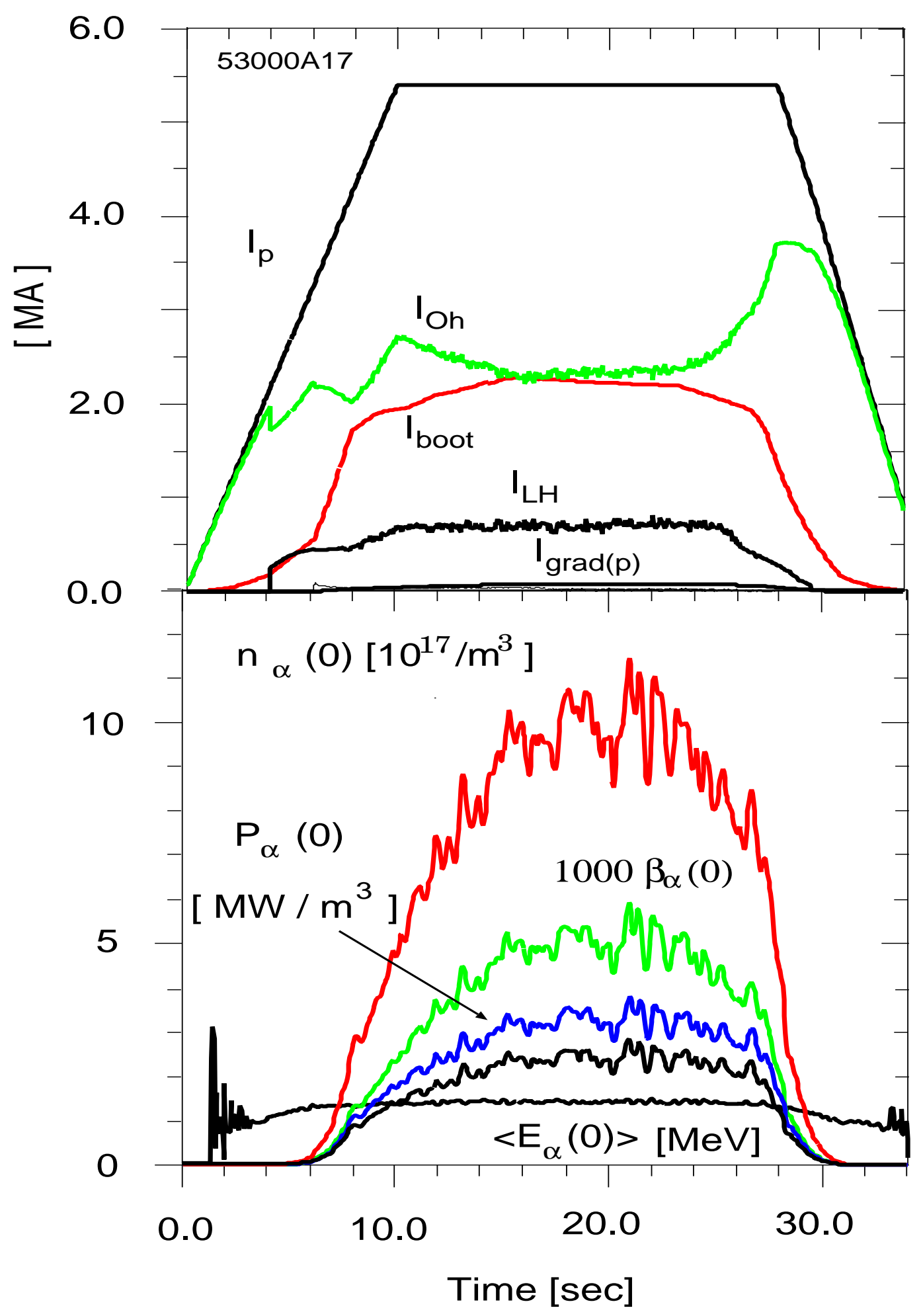

Figure 2. Evolution of the surface-area-integrated currents and central alpha parameters in the FIRE AT plasma. 


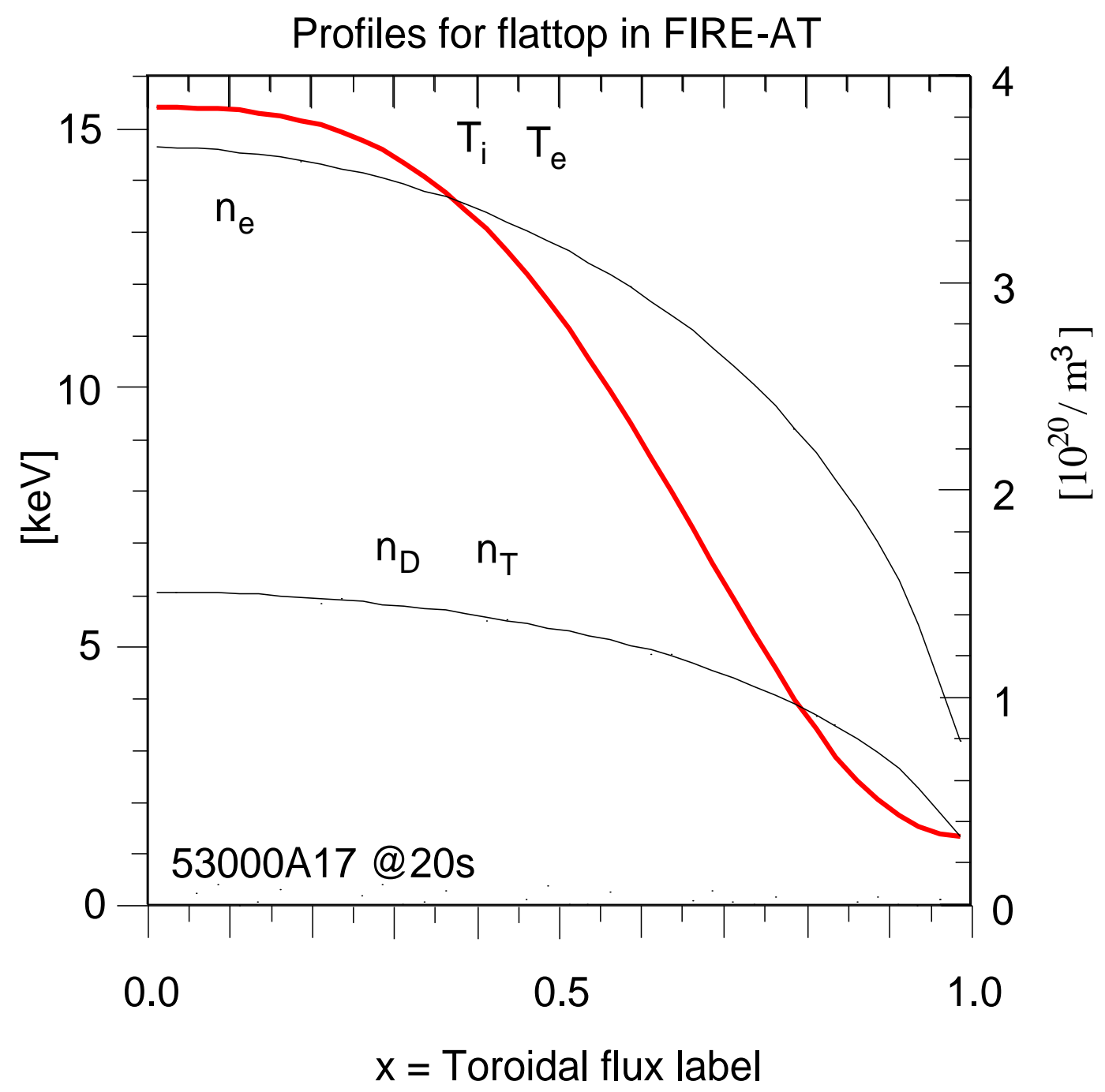

Figure 3. Profiles of steady-state plasma temperatures and densities assumed for the FIRE AT plasma. 


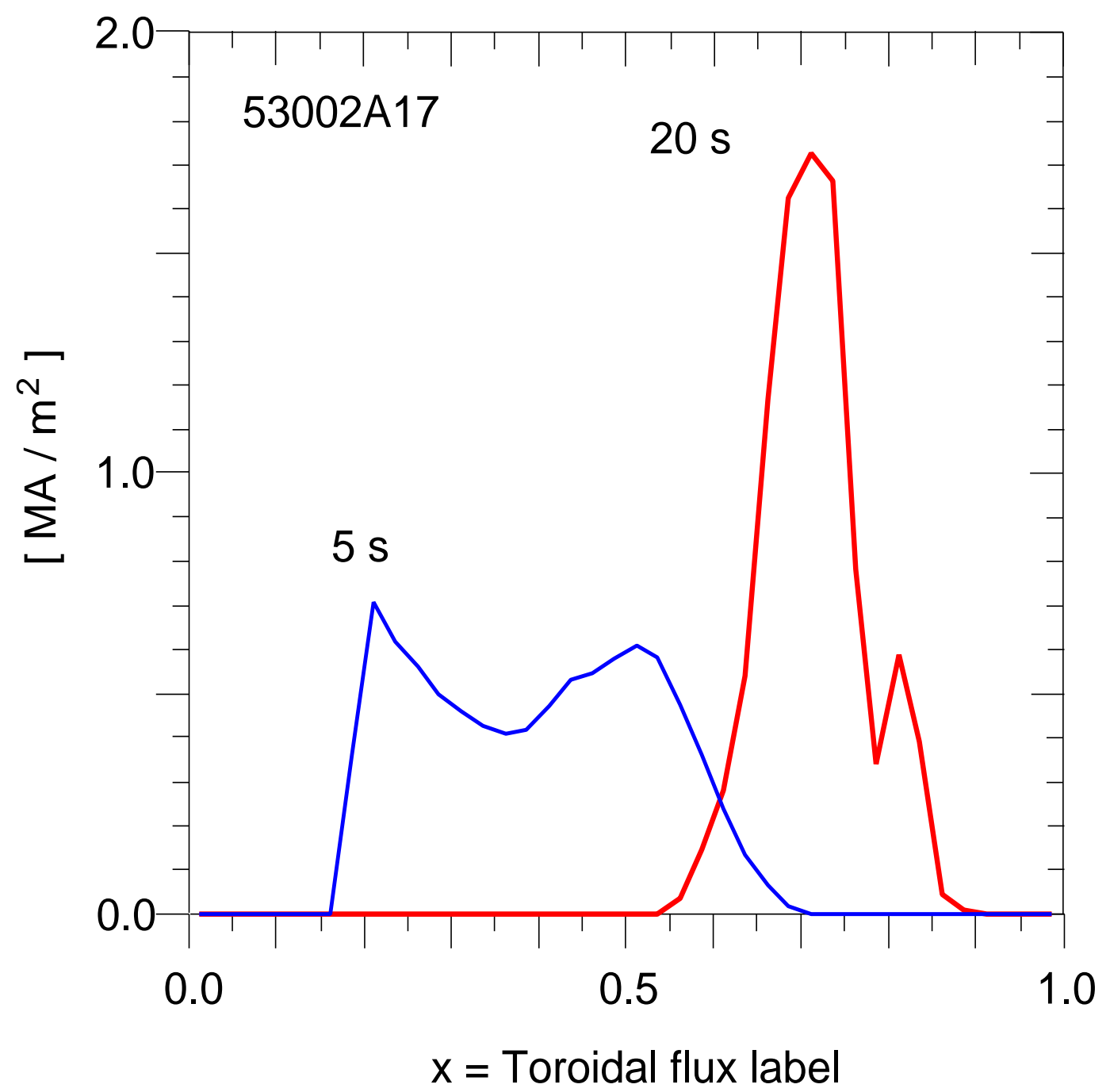

Figure 4. Profiles of lower-hybrid-driven currents in the FIRE AT. The driven current moves out in radius as the density and temperatures increase to their steady state values. 


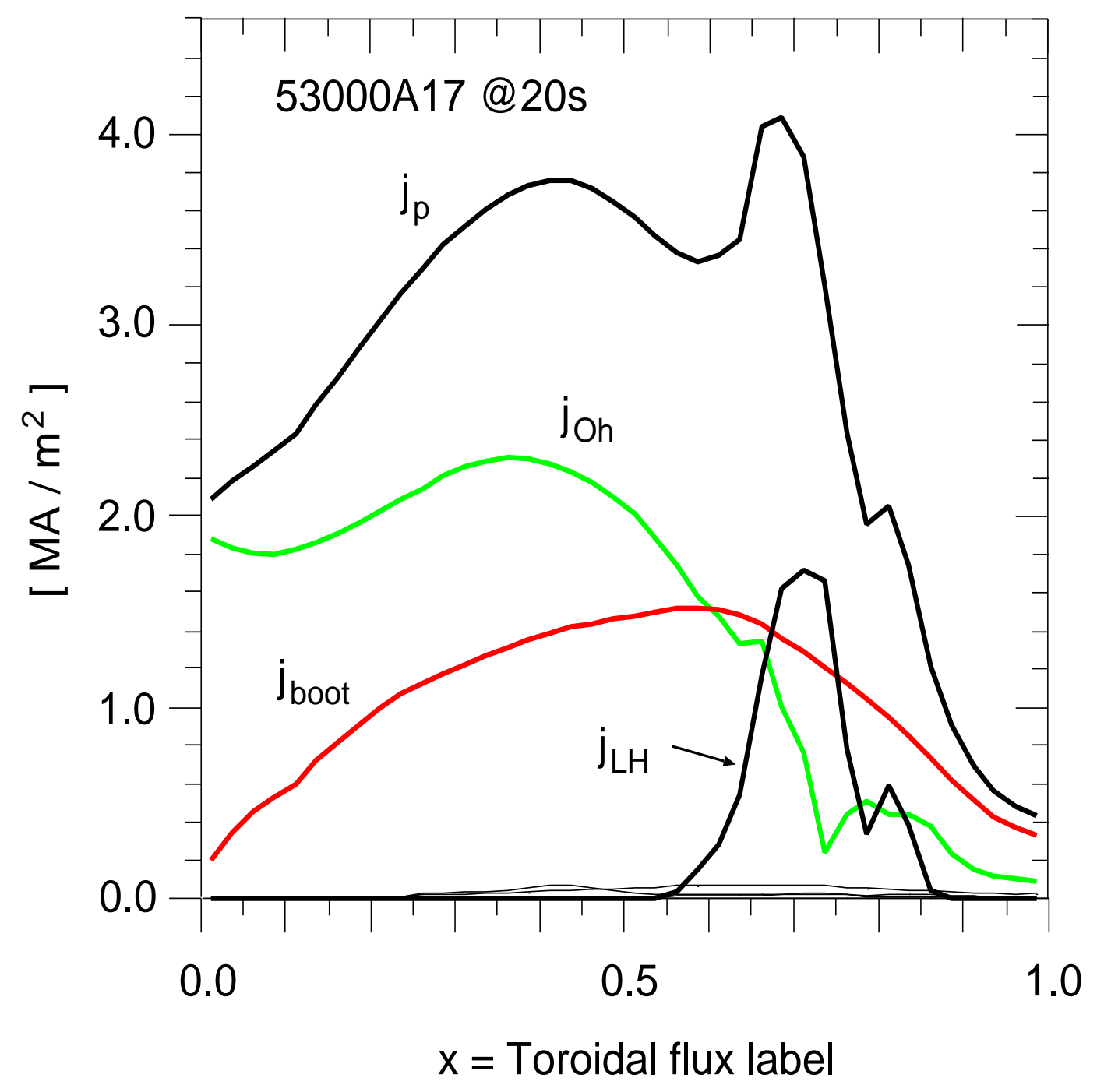

Figure 5. Profiles of plasma currents in the FIRE AT plasma. 


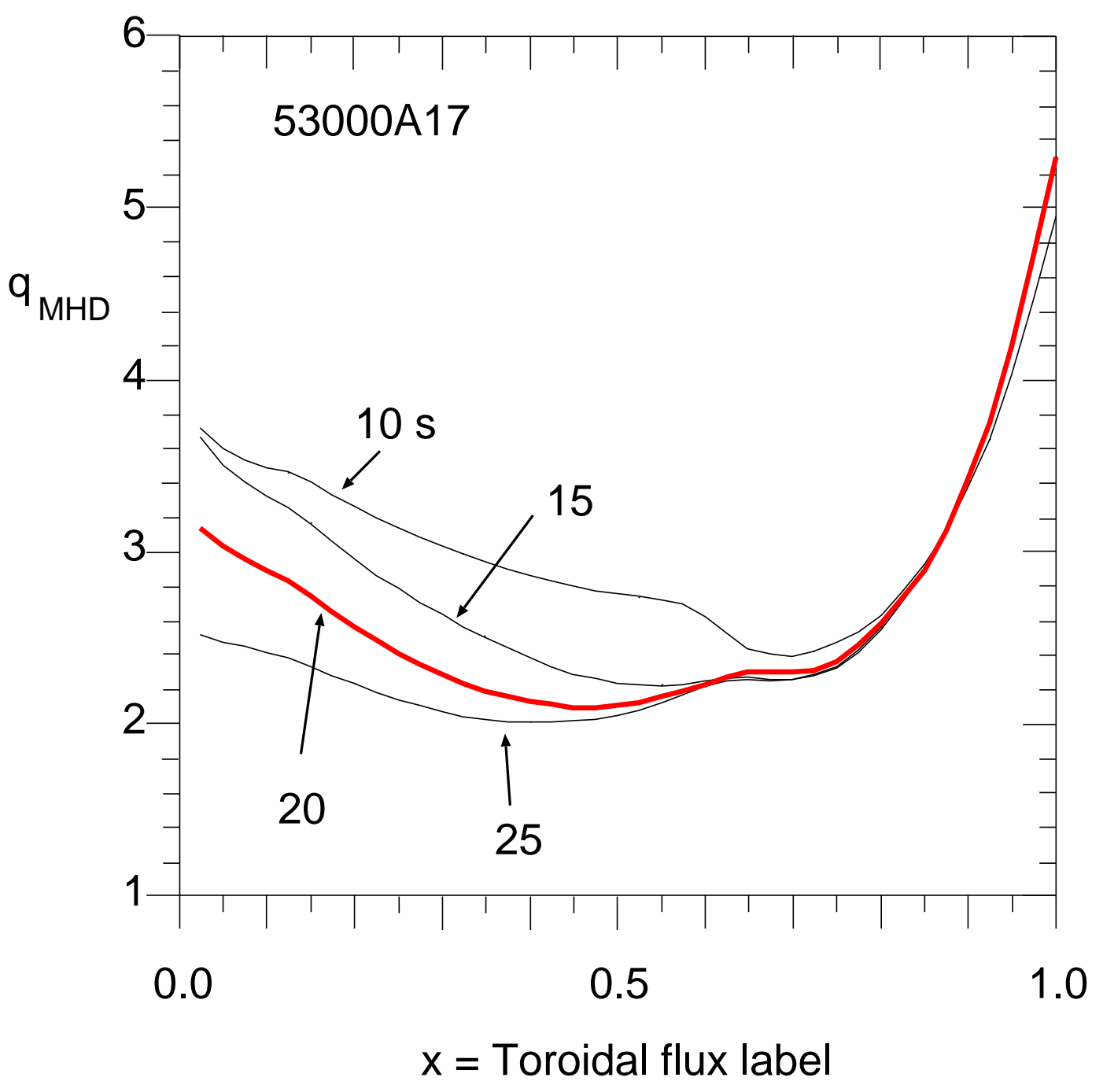

Figure 6. Profiles of $q_{M H D}$ in the FIRE AT plasma. 


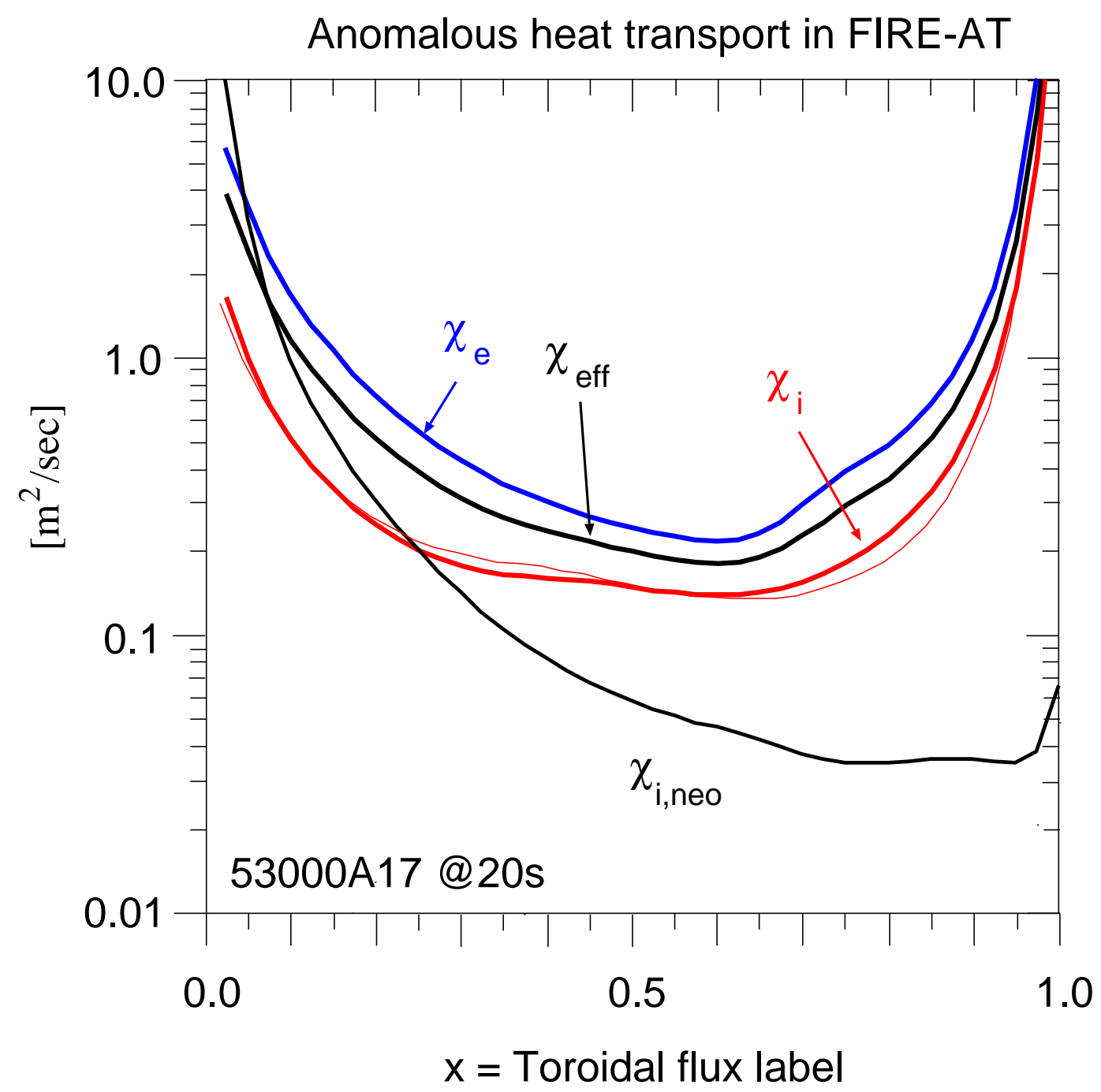

Figure 7. Profiles of thermal energy transport coefficients computed for the FIRE AT plasma. The neoclassical ion transport profile is calculated using the NCLASS model [11] incorporated in TRANSP. The FIRE AT plasma is conservative in the sense that the ion transport rate is much larger than $\chi_{i, n e o}$. The faint $\chi_{\mathrm{i}}$ line gives the profile for the case where there is no NBI heating but with the same plasma profiles. 


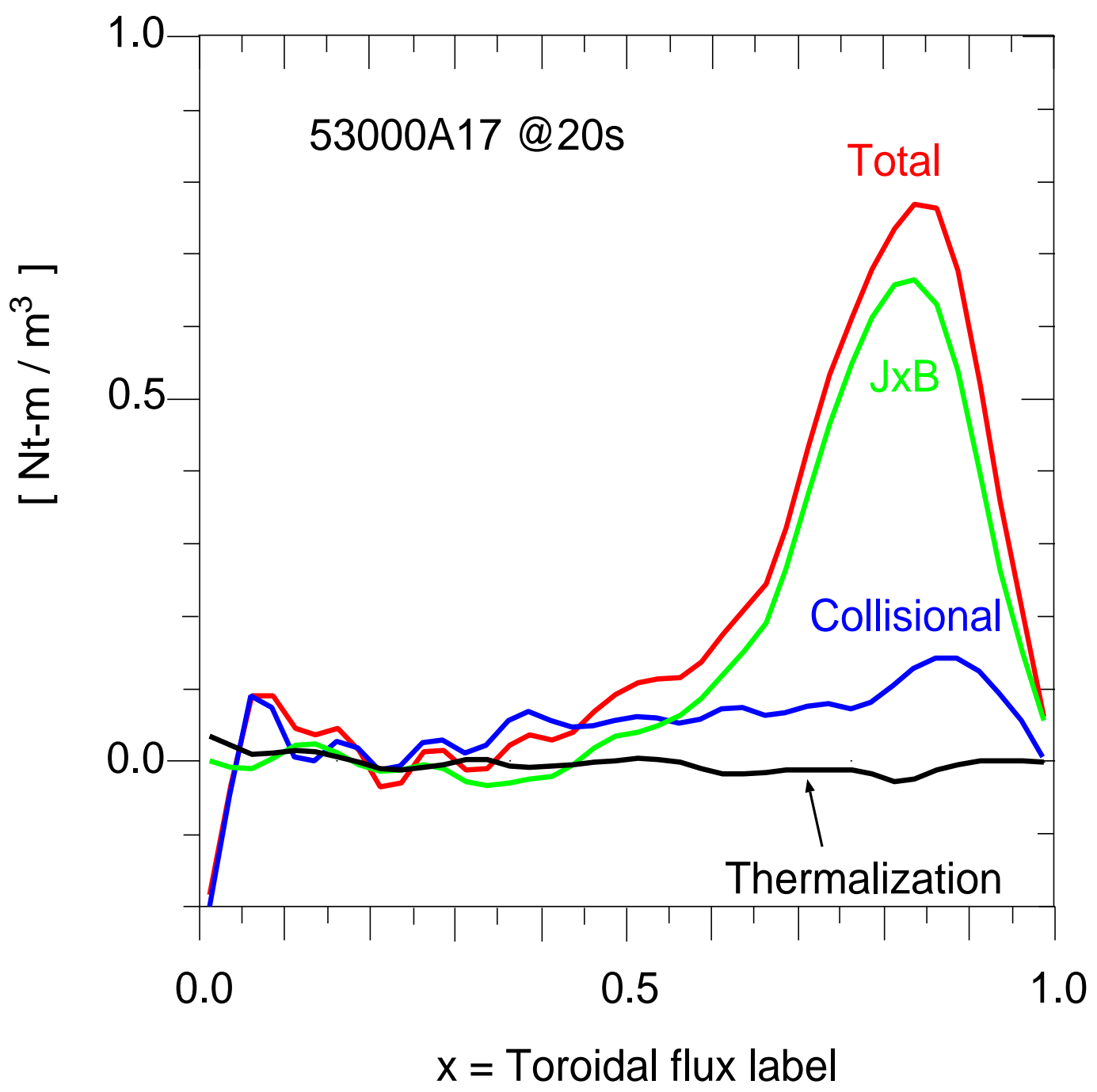

Figure 8. Profiles of NBI-induced torque densities on the FIRE AT plasma. The total is dominated by the JxB contribution near the edge. 


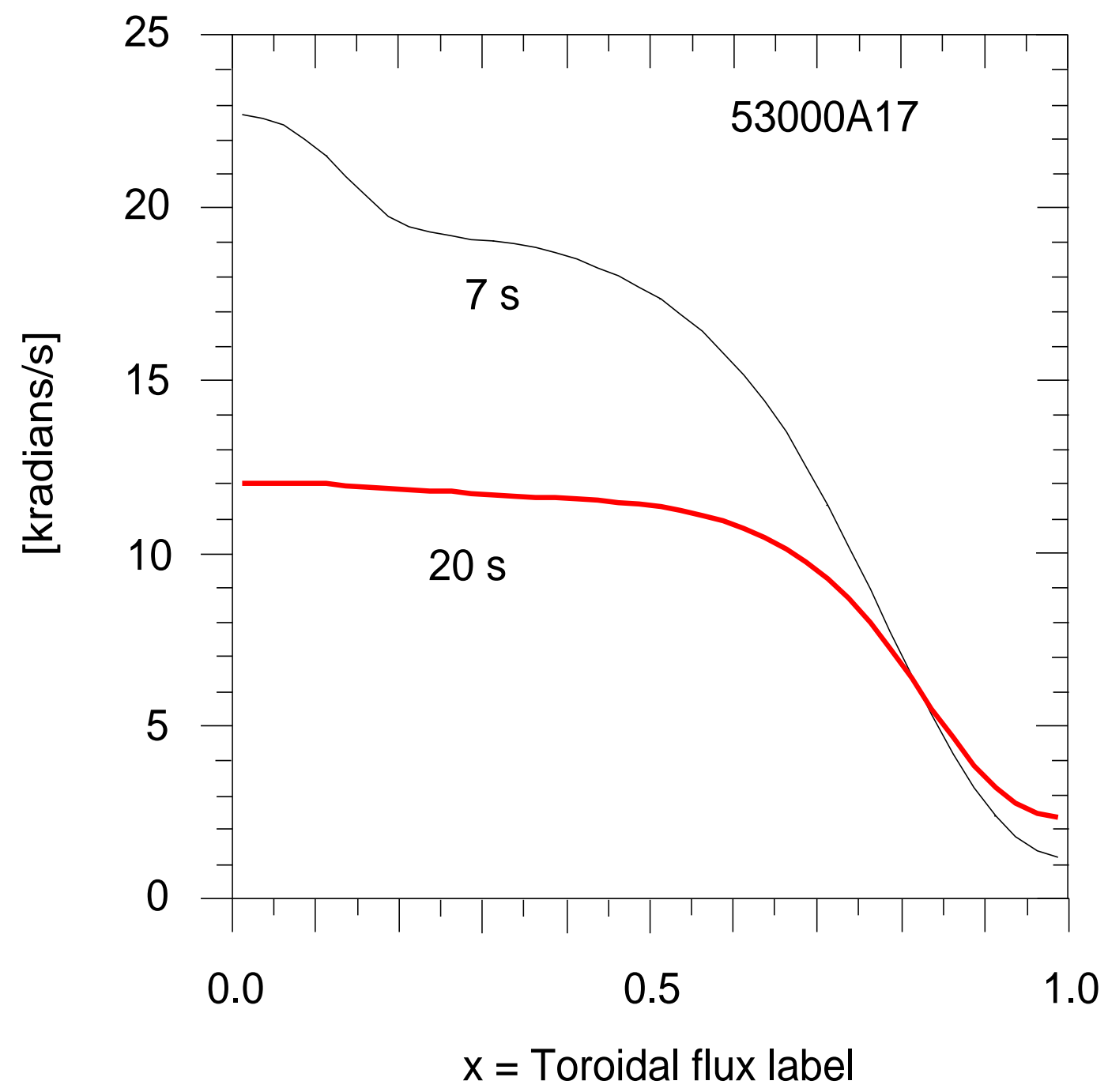

Figure 9. Profiles of the toroidal rotation computed for the FIRE AT plasma. Note that $\omega_{t o r}$ is relatively high before the plasma density ramps up to the steady state profile. 


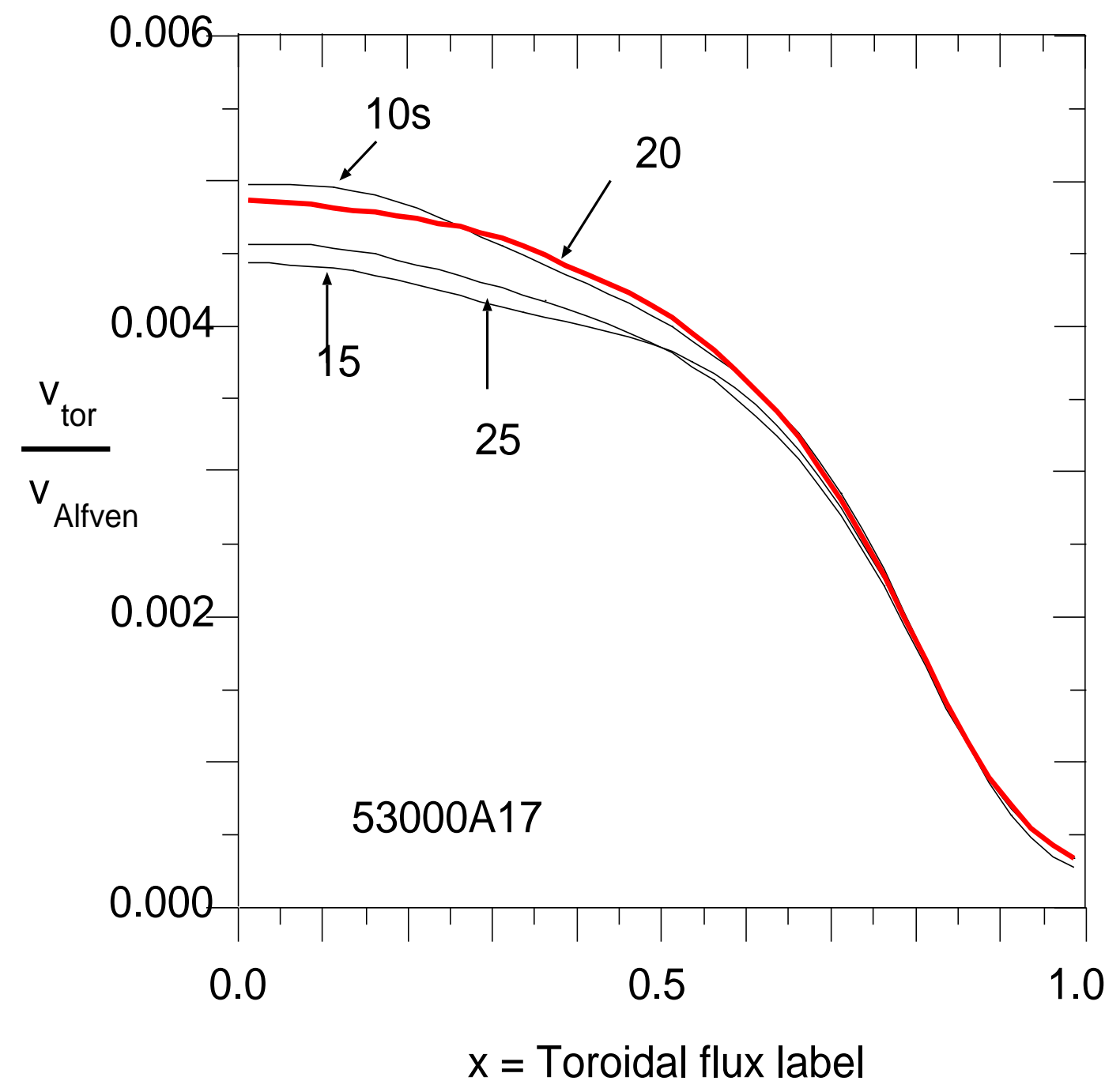

Figure 10. Profiles of the ratio of the toroidal rotation to Alfvén speeds in the FIRE AT plasma. 


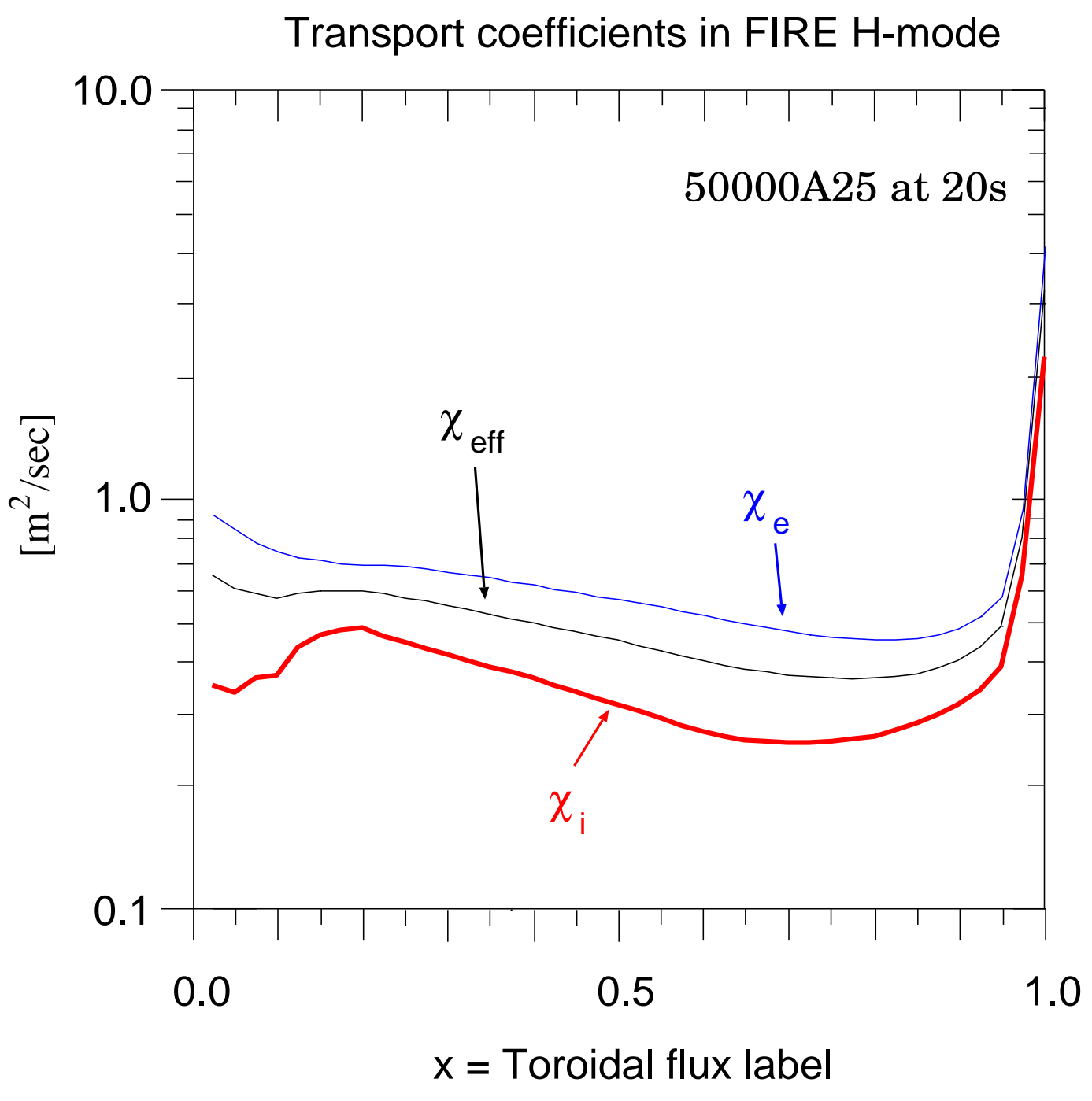

Figure 11. Profiles of heat transport diffusion coefficients computed for the FIRE H-mode plasma. 


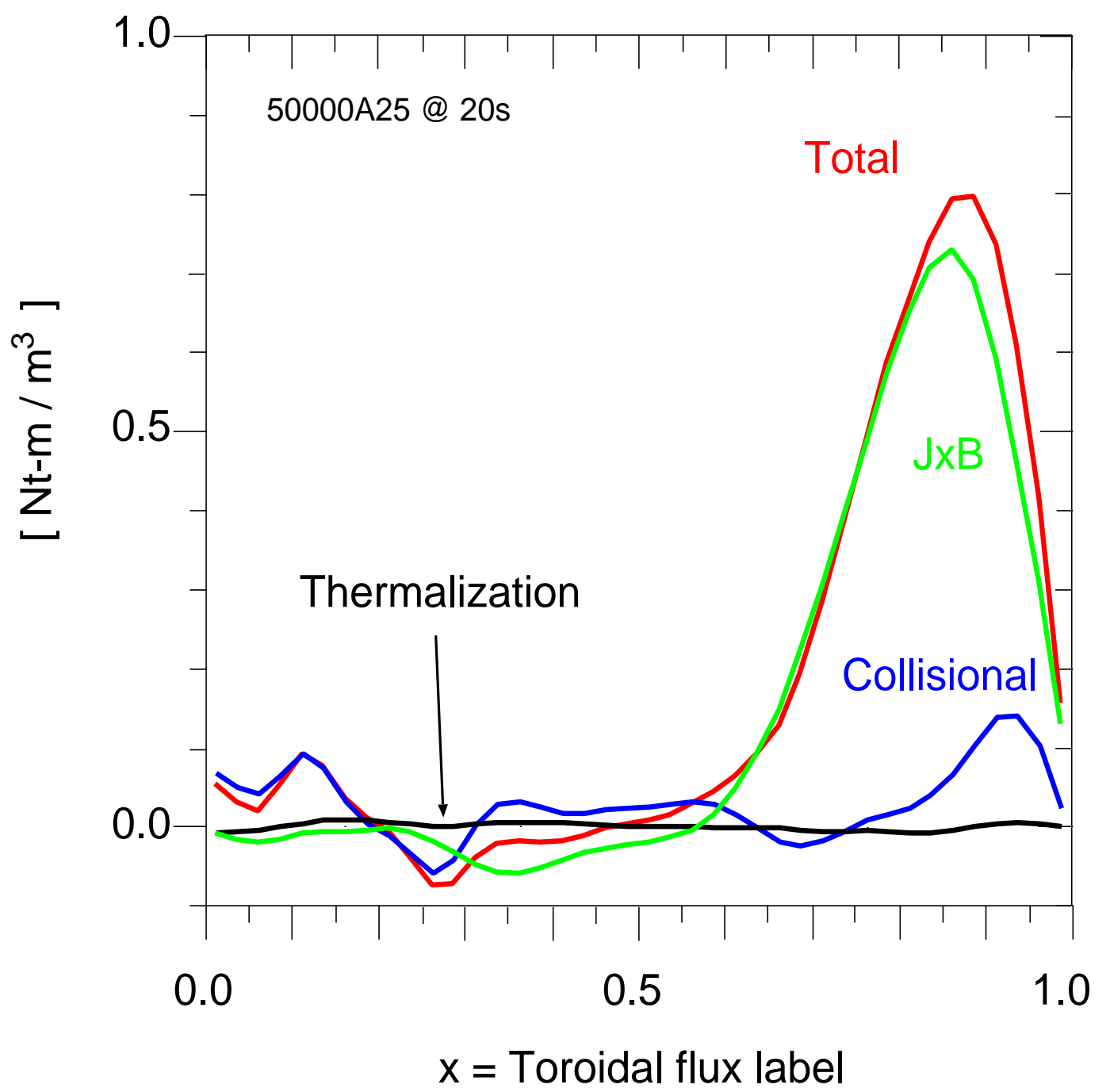

Figure 12. Profiles of NBI-induced torque densities in the FIRE H-mode plasma. The total is dominated by the JxB contribution near the edge. 


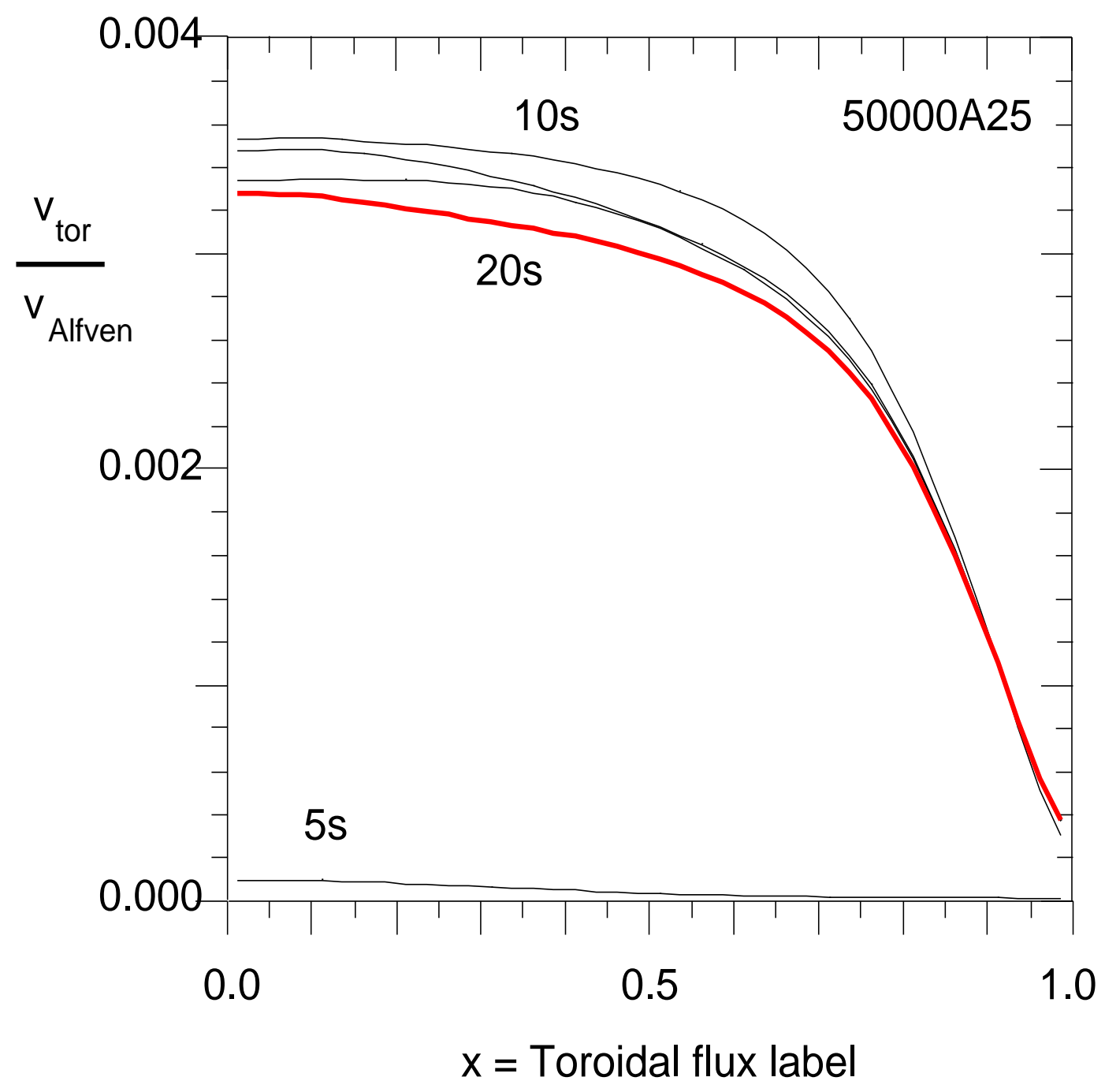

Figure 13. Profiles of the ratio of the toroidal rotation to Alfvén speeds in the FIRE H-mode plasma. 


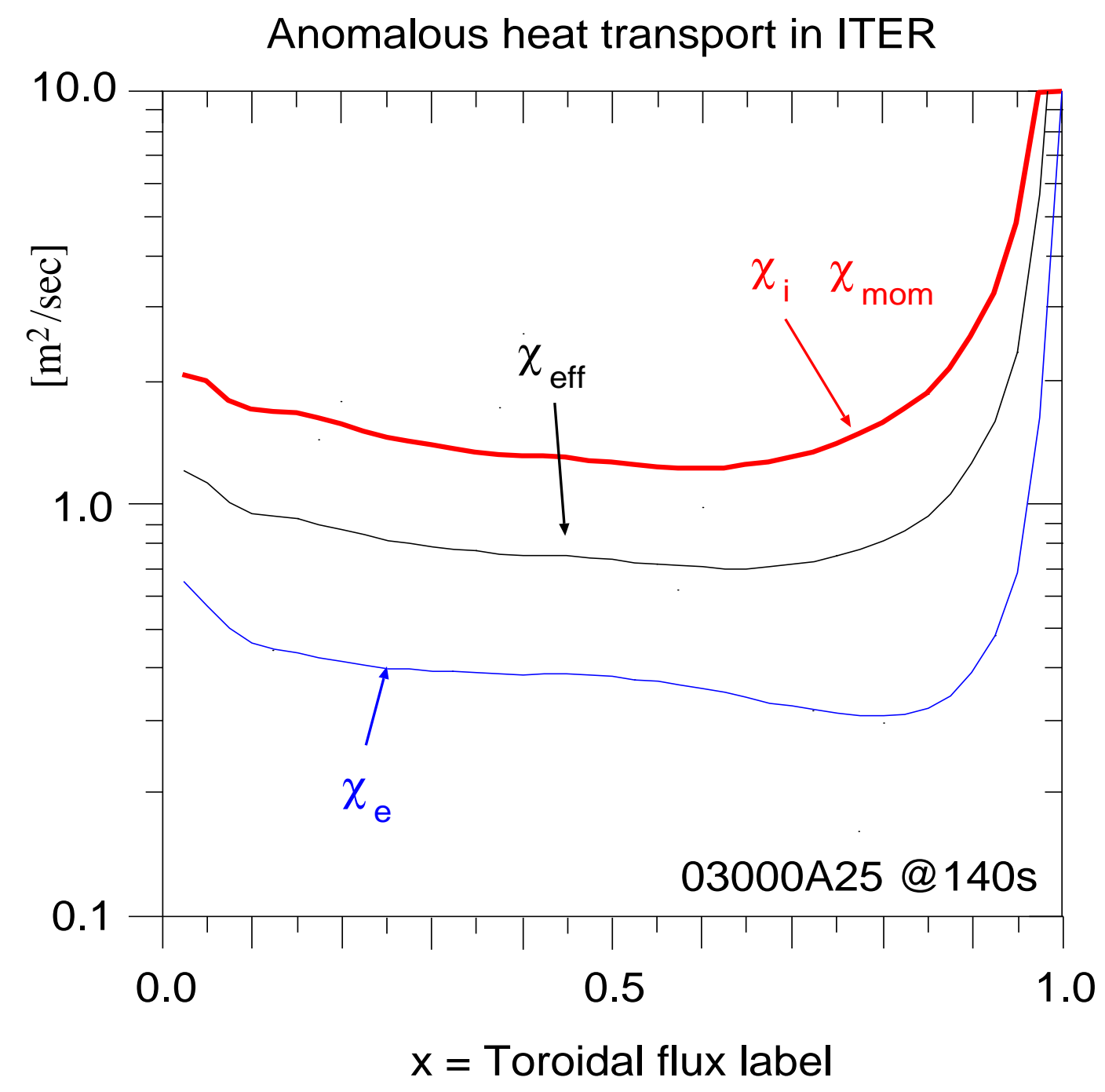

Figure 14. Profiles of the heat transport diffusion coefficients in the ITER-FEAT H-mode plasma. 


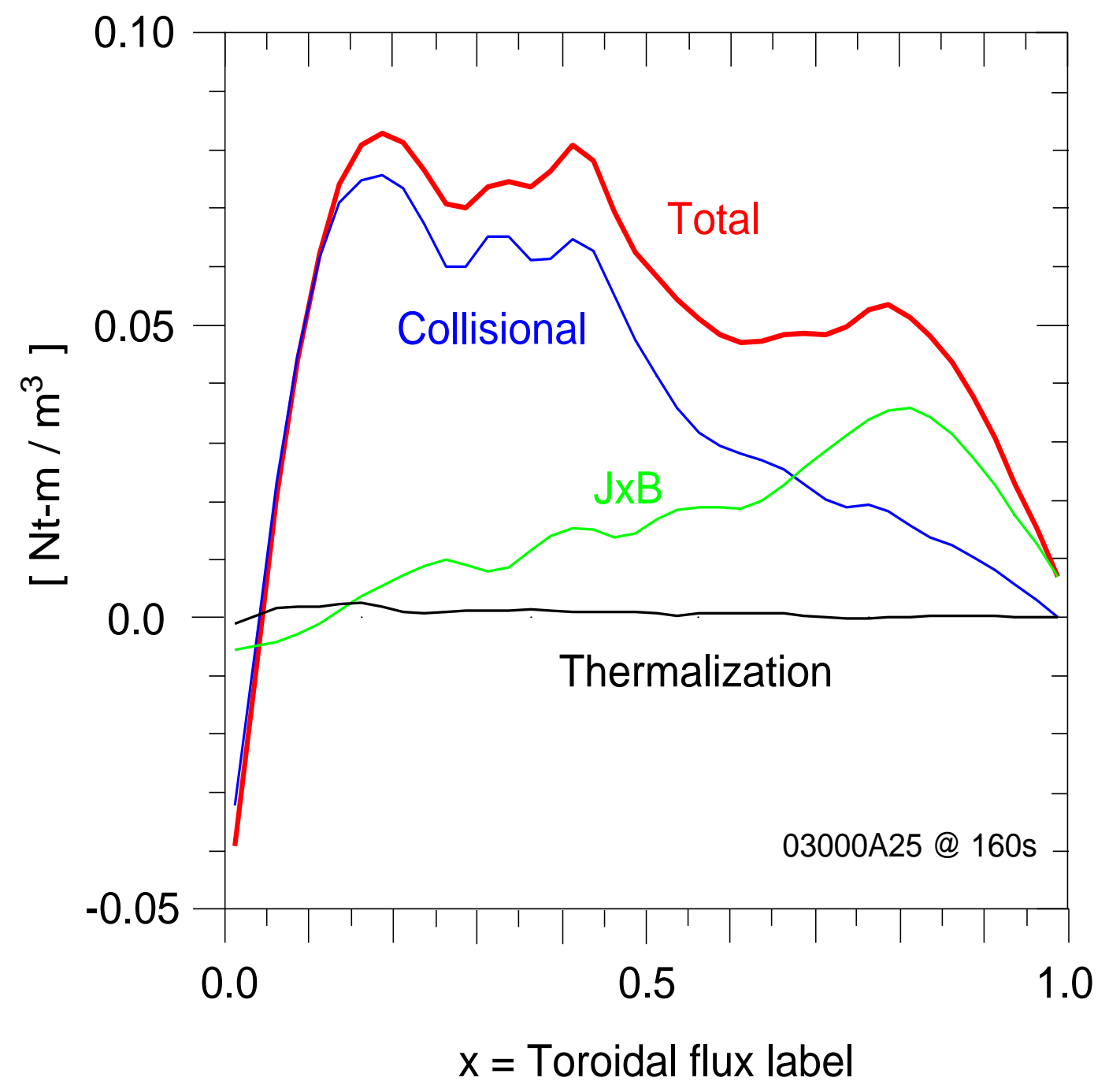

Figure 15. Profiles of NNBI-induced torque densities on the ITER-FEAT H-mode plasma. The total is dominated by the collisional drag in the core and the $\mathrm{JxB}$ contribution near the edge. 


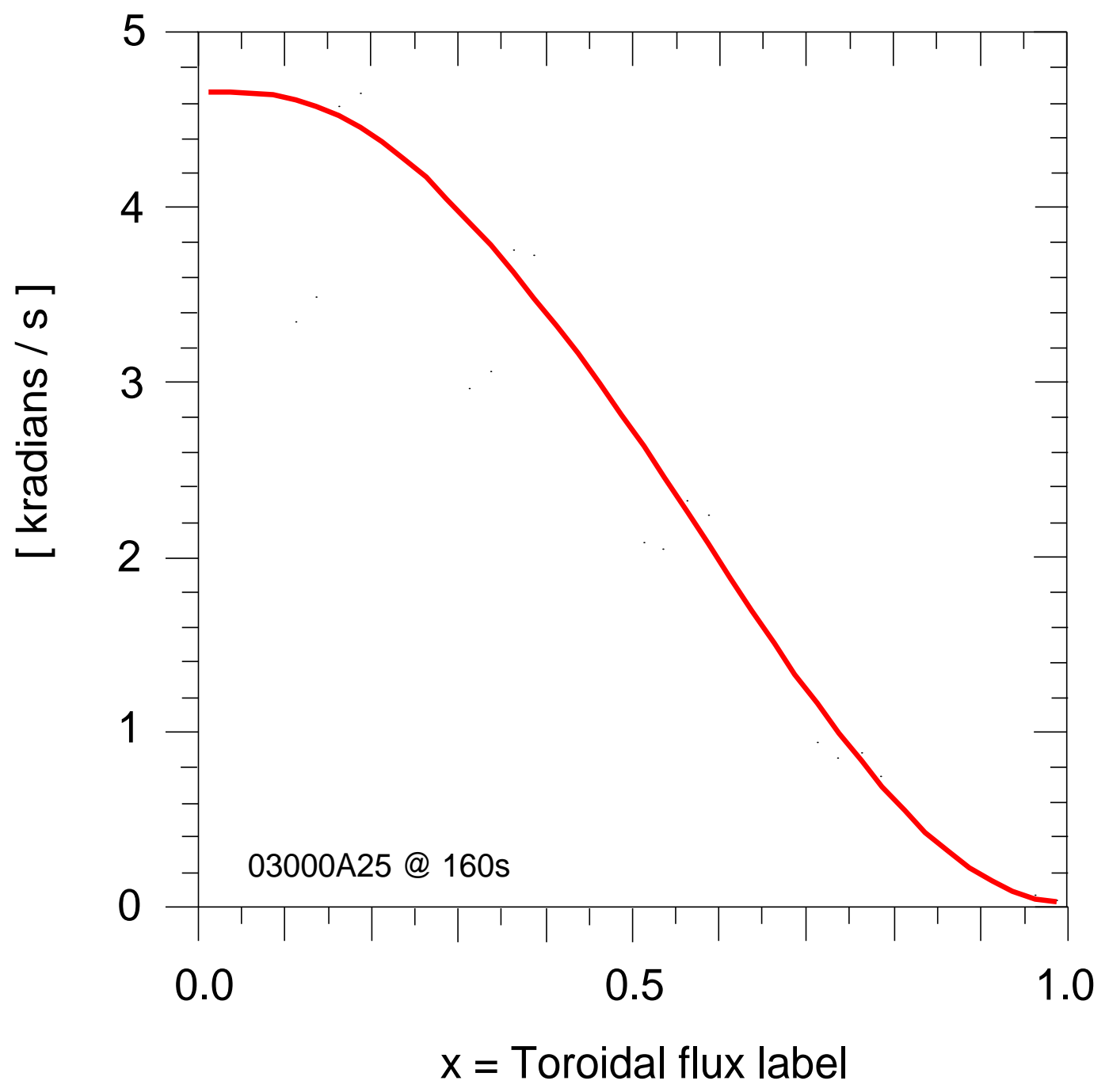

Figure 16. Profile of the toroidal rotation rate in the ITER-FEAT H-mode plasma assuming $\chi_{\phi}=\chi_{i}$. 


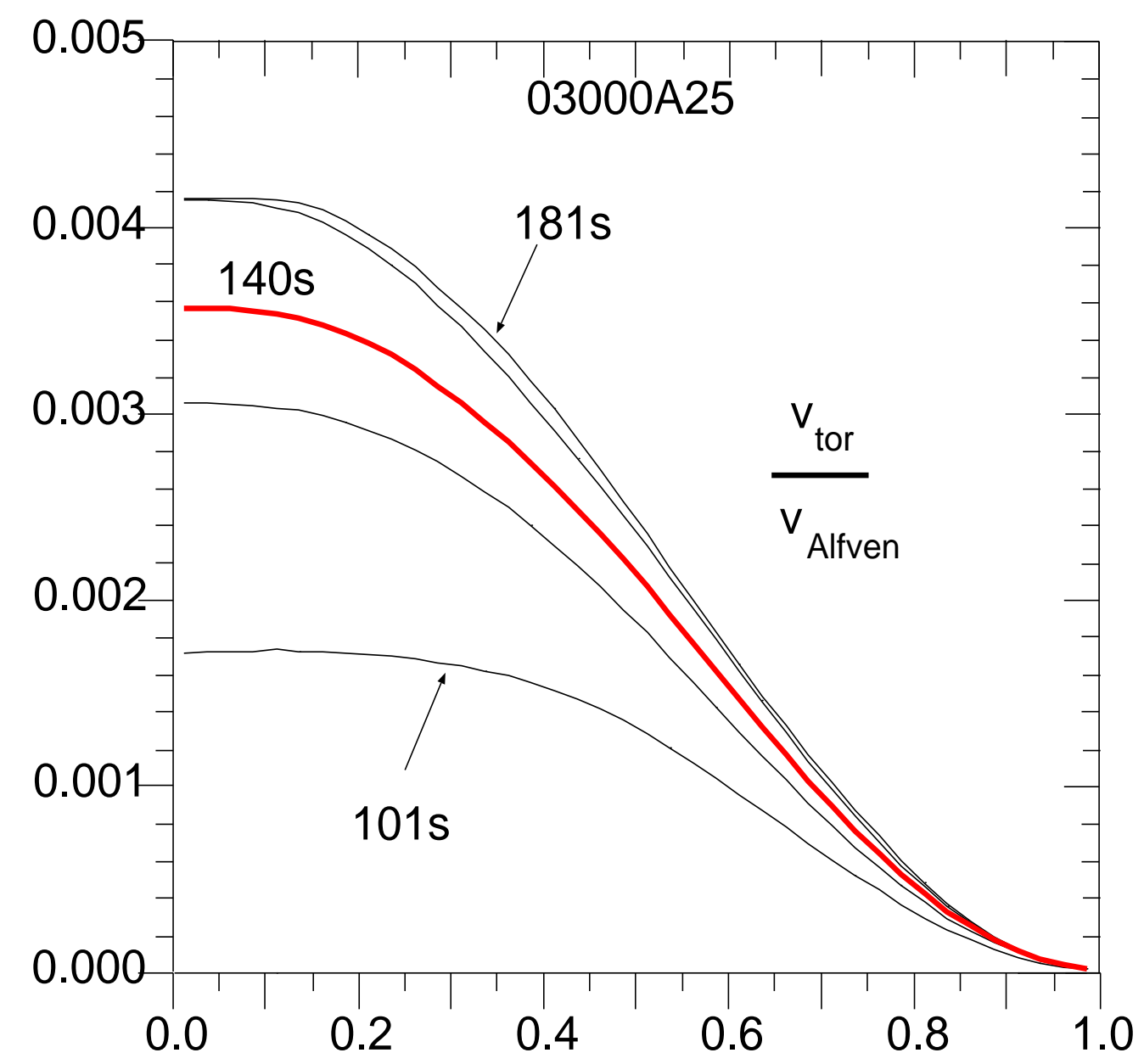

Hydrog vel over Alfv vel (VEL_ALF ) VS. x"r/a" ctr

Figure 17. Profile of the ratio of the toroidal rotation to Alfvén speeds in the ITER-FEAT H-mode plasma assuming $\chi_{\phi}=\chi_{i}$. 


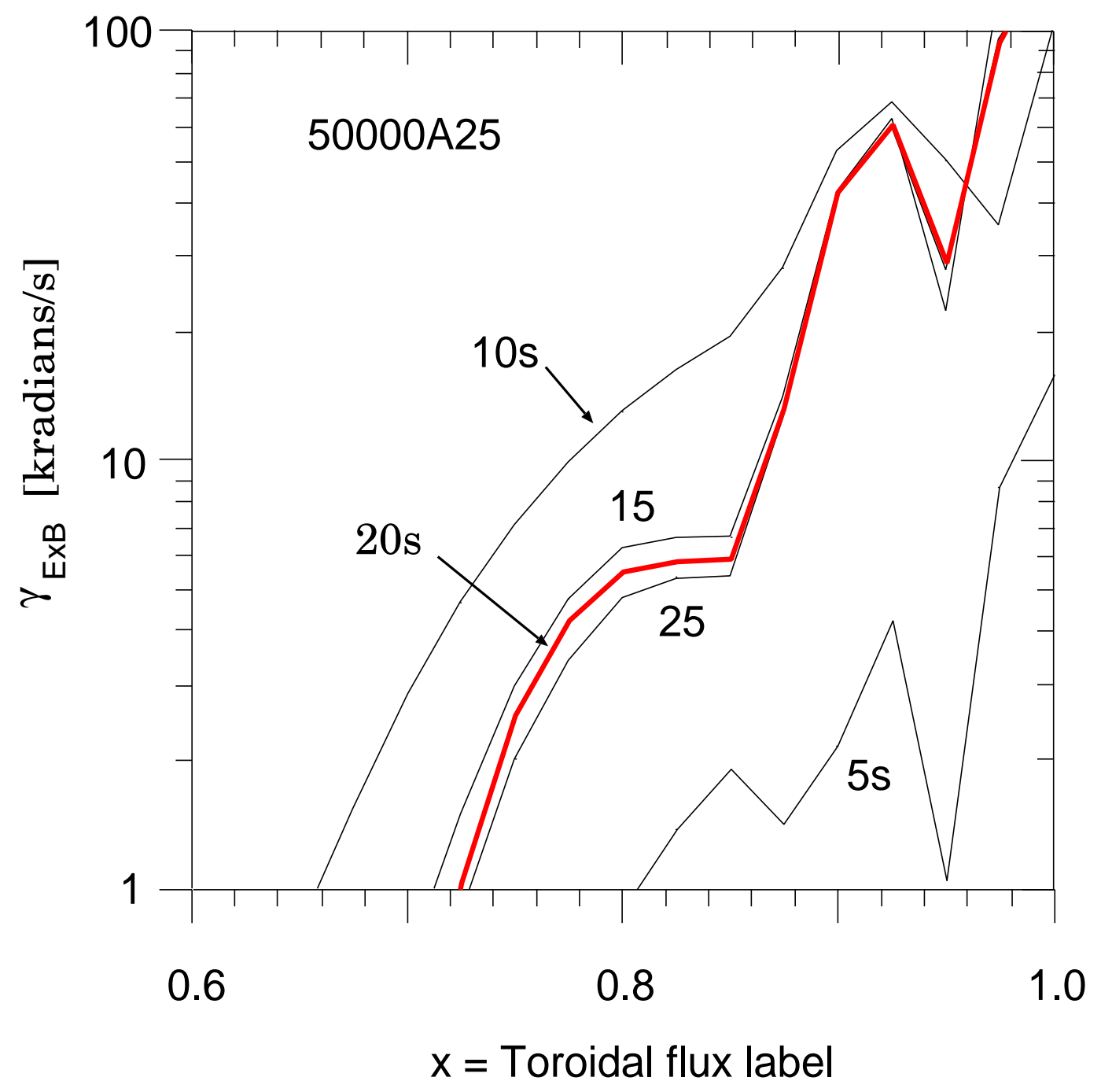

Figure 18. Profiles of the NBI-induced flow shearing rate in the FIRE H-mode plasma. 


\section{External Distribution}

Plasma Research Laboratory, Australian National University, Australia

Professor I.R. J ones, Flinders University, Australia

Professor J oão Canalle, Instituto de Fisica DEQ/IF - UERJ , Brazil

Mr. Gerson O. Ludwig, Instituto Nacional de Pesquisas, Brazil

Dr. P.H. Sakanaka, Instituto Fisica, Brazil

The Librarian, Culham Laboratory, England

Library, R61, Rutherford Appleton Laboratory, England

Mrs. S.A. Hutchinson, JET Library, England

Professor M.N. Bussac, Ecole Polytechnique, France

Librarian, Max-Planck-Institut für Plasmaphysik, Germany

J olan Moldvai, Reports Library, MTA KFKI-ATKI, Hungary

Dr. P. Kaw, Institute for Plasma Research, India

Ms. P.J . Pathak, Librarian, Insitute for Plasma Research, India

Ms. Clelia De Palo, Associazione EURATOM-ENEA, I taly

Dr. G. Grosso, Instituto di Fisica del Plasma, Italy

Librarian, Naka Fusion Research Establishment, J AERI, J apan

Library, Plasma Physics Laboratory, Kyoto University, J apan

Research Information Center, National Institute for Fusion Science, J apan

Dr. O. Mitarai, Kyushu Tokai University, J apan

Library, Academia Sinica, Institute of Plasma Physics, People's Republic of China

Shih-Tung Tsai, Institute of Physics, Chinese Academy of Sciences, People's Republic of China

Dr. S. Mirnov, TRINITI, Troitsk, Russian Federation, Russia

Dr. V.S. Strelkov, Kurchatov Institute, Russian Federation, Russia

Professor Peter Lukac, Katedra Fyziky Plazmy MFF UK, Mlynska dolina F-2, Komenskeho Univerzita, SK-842 15 Bratislava, Slovakia

Dr. G.S. Lee, Korea Basic Science Institute, South Korea

Mr. Dennis Bruggink, Fusion Library, University of Wisconsin, USA

Institute for Plasma Research, University of Maryland, USA

Librarian, Fusion Energy Division, Oak Ridge National Laboratory, USA

Librarian, Institute of Fusion Studies, University of Texas, USA

Librarian, Magnetic Fusion Program, Lawrence Livermore National Laboratory, USA

Library, General Atomics, USA

Plasma Physics Group, Fusion Energy Research Program, University of California at San Diego, USA

Plasma Physics Library, Columbia University, USA

Alkesh Punjabi, Center for Fusion Research and Training, Hampton University, USA

Dr. W.M. Stacey, Fusion Research Center, Georgia Institute of Technology, USA

Dr. J ohn Willis, U.S. Department of Energy, Office of Fusion Energy Sciences, USA

Mr. Paul H. Wright, Indianapolis, Indiana, USA 
The Princeton Plasma Physics Laboratory is operated by Princeton University under contract with the U.S. Department of Energy.

\author{
Information Services \\ Princeton Plasma Physics Laboratory \\ P.O. Box 451 \\ Princeton, NJ 08543
}

Phone: 609-243-2750

Fax: 609-243-2751

e-mail: pppl_info@pppl.gov

Internet Address: http://www.pppl.gov 